\title{
Introduction of Large Volumes of Methylene Chloride in Capillary GC with Electron Capture Detection
}

\author{
Jacek Staniewski ${ }^{1}$, Hans-Gerd Janssen*, Jacques A. Rijks \\ and Carel A. Cramers \\ Eindhoven University of Technology, Faculty of Chemical Engineering \\ Laboratory of Instrumental Analysis, P.O. Box 513, $5600 \mathrm{MB}$ \\ Eindhoven, The Netherlands
}

\begin{abstract}
In this paper, a system is presented that allows direct introduction of large volumes of methylene chloride in capillary gas chromatography (GC) using the electron capture detector (ECD). The system is based on a two-dimensional (one-oven) GC instrument equipped with a programmed temperature injector. During sample introduction, the solvent is eliminated via the split line. Residual traces of methylene chloride that enter the precolumn are eliminated via a column-switching device located between the precolumn and the analytical column. The system is used for the analysis of pesticides and polychlorinated biphenyls (PCBs) in methylene chloride at ultra low concentrations. The introduction of large sample volumes significantly improved the detection limits. Using the system described here, the solvent exchange step, normally necessary when the ECD is used to analyze samples containing methylene chloride as the solvent, is no longer required.
\end{abstract}

Key words: large volume injections, PTV injector, electron capture detection, multidimensional gas chromatography

\section{INTRODUCTION}

The separation and analysis of low concentrations of organic compounds in complex sample matrices often require the use of specific and/or highly sensitive detectors. Moreover, extensive sample preparation (e.g., extraction, preconcentration, phase switching, clean-up) is often necessary. In the past, the electron capture detector (ECD) proved to be a very sensitive, selective, and reliable detector. For these reasons the ECD is now one of the most frequently used detectors in environmental analysis. A distinct disadvantage of the $\mathrm{ECD}$, however, is its incompatibility with halogencontaining solvents. Even trace amounts of these solvents can deactivate the detector for prolonged periods.

The incompatibility of the solvent and the detection system employed can be solved by complete removal of the solvent before it reaches the detector. Schomburg [1] described a method in which removal of the solvent vapors prior to the ECD was effected by reversing the direction of the flow of make-up gas during elution of the solvent. Tomberg et al. [2] reported protection of an alkali flame ionization detector from methylene chloride vapors by installation of a press-fit $Y$-connector at the column outlet. Solvent vapors were eliminated by applying a vacuum to the vapor exit during passage of the solvent.

The use of chromatographic heart-cutting techniques is a sophisticated method of exclusion of the solvent from the chromatographic pathway. Using a two-dimensional two-oven system with a rotary valve, Sonchik [3] demonstrated the selective removal of the methylene chloride solvent in the analysis of polychlorinated biphenyls (PCBs). The method was only applied to split injection of

Presented at the 15th International Symposium on Capillary Chromatography, Riva del Garda, Italy, May 1993

*Author to whom correspondence should be addressed

${ }^{1}$ Also at Poznań Technical University, Institute of Chemical Technology and Engineering, M. Sklodowskiej-Curie 2, 60-965

Poznań, Poland

1993 MicroSeparations 

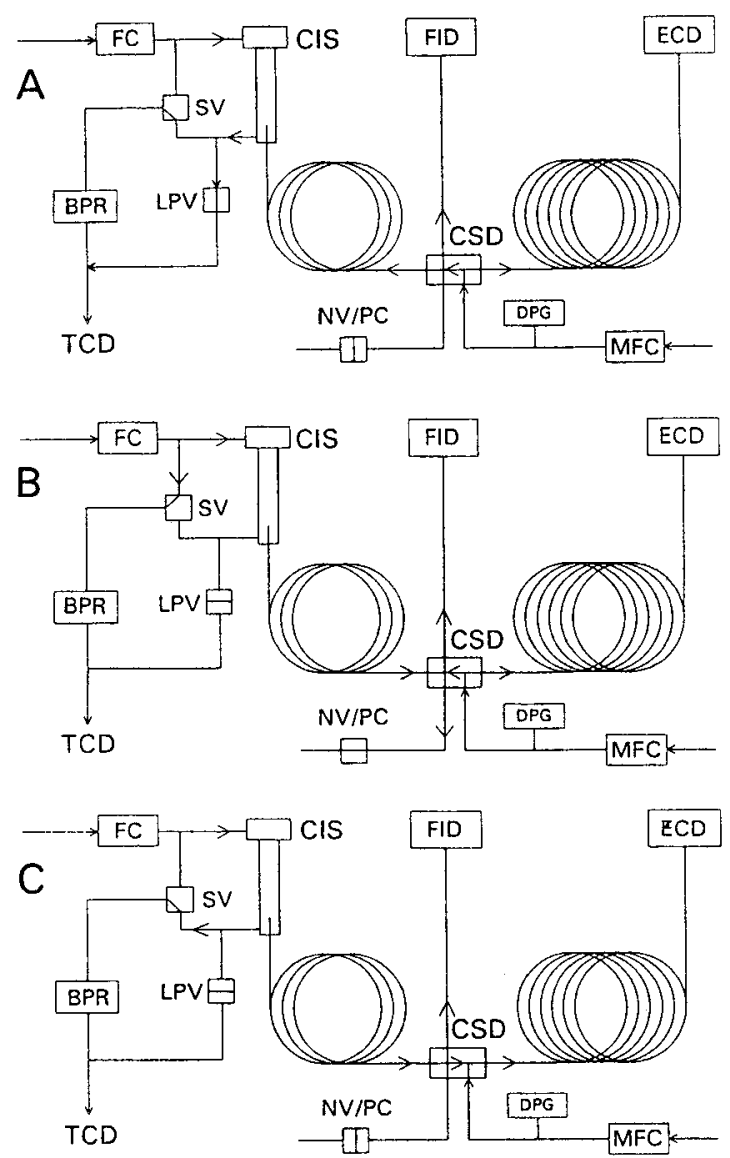

Figure 1. Schematic diagram of the solvent elimination GC instrumentation. Modes: (A) solvent elimination via the split vent and back-flush of the precolumn, (B) removal of traces of residual solvent by heart cutting, and (C) chromatographic analysis. (CIS) programmed temperature injection system, (FC) flow controller, (BPR) back-pressure regulator, (SV) split/splitless valve, (LPV) low pressure valve, (CSD) column-switching device, (MFC) mass flow controller, (DPG) digital pressure gauge, (NV/PC) needle valve with a pneumatic controller.

very small sample volumes. The applicability of the system for the elimination of larger volumes was not investigated.

In this article, a system is presented that allows direct introduction of very large volumes of methylene chloride in capillary gas chromatography (GC) with electron capture detection. The system is based on a two-dimensional one-oven GC instrument equipped with a programmed temperature injector (PTV). The applicability of the system is demonstrated by the analysis of a number of environmentally relevant samples.

\section{EXPERIMENTAL}

Instrumentation. The GC system used in the experimental part of this work consisted of a gas chromatograph (HP 5890 Series II, Hewlett-Packard, Avondale, PA, USA), a PTV (CIS-3, Gerstel $\mathrm{GmbH}$, Mülheim a/d Ruhr, Germany), and a dual column switching module (DCS, Gerstel GmbH). The GC instrument was equipped with an ECD (as the main detector) and an FID. The entire system was operated under computer control using MCS software (Gerstel $\mathrm{GmbH}$ ). An Omega System (Perkin Elmer, Norwalk, CT, USA) was used for data acquisition.

The PTV was equipped with a deactivated liner containing a porous bed of sintered glass beads $[4,5]$. The split vent line of the injection system was modified in the same manner as described elsewhere $[4,5]$. This modification allowed elimination of the solvent at low pressures and high purge gas flow rates (up to about $600 \mathrm{~mL} \mathrm{~min}-1$ ). An external thermal conductivity detector (Gow Mac, Bridgewater, NJ, USA) installed in the split line of the injector was used to monitor the solvent elimination process. A schematic diagram of the system is given in Figure 1. The flow paths in the different modes are discussed below.

The methylene chloride sample is introduced into the liner of the programmable injector at a controlled speed. During sample introduction the solvent is eliminated via the split line by applying a high flow of purge gas at a reduced inlet pressure. In this stage of the sample introduction process, the precolumn is back-flushed in order to prevent transfer of methylene chloride into the column. The flow paths and valve settings during the introduction of the sample into the liner are shown in Figure 1A. After completion of the solvent elimination process, the components retained in the liner of the injector are transferred to the precolumn in the splitless mode. Residual traces of methylene chloride that also entered the precolumn are removed by chromatographic heartcutting. The flow paths during transfer with heartcutting are shown in Figure 1B. After fully eliminating the solvent by heart-cutting, the needle valve in the vent line of the column switching device is closed and the temperature programs of the programmable injector and the gas chromatograph are started. The valve settings and directions of the gas flows during the analysis are shown in Figure 1C.

Operating conditions. Sample volumes below $25 \mu \mathrm{L}$ were introduced manually. Large volume samples of PCBs and pesticides were introduced into the liner of the injector by means of a microprocessor-controlled syringe pump (SPS-1, Gerstel 
$\mathrm{GmbH}$ ). With this system, sample volumes up to $1 \mathrm{~mL}$ could be introduced at introduction rates between 1 and $2000 \mu \mathrm{L} \mathrm{min}{ }^{-1}$. Solvent elimination in the PTV was carried out in the solvent split mode applying a purge gas flow rate of $620 \mathrm{~mL} \mathrm{~min}^{-1}$ at a reduced inlet pressure of $20 \mathrm{kPa}$. The initial temperature of the injector was $0^{\circ} \mathrm{C}$. Under these operating conditions the maximal allowable sample introduction rate was estimated to be approximately $100 \mu \mathrm{L}$ min $^{-1}$ [6]. After solvent elimination, the split vent was left in the open position for an additional $10 \mathrm{~s}$ to allow the last parts of the solvent to evaporate. Next, the split exit was closed, the inlet pressure was increased to the normal value, and the programmable injector was heated to its final temperature of $280^{\circ} \mathrm{C}$ at a rate of $12^{\circ} \mathrm{C} \mathrm{s}^{-1}$. The final time at this temperature was 1 min. The splitless time applied was 0.75 $\min$.

The separation of the pesticide sample was carried out using a $5 \mathrm{~m} \mathrm{x}$ $0.32 \mathrm{~mm}$ i.d. precolumn and a $25 \mathrm{~m} \mathrm{x}$ $0.32 \mathrm{~mm}$ i.d. analytical column. The precolumn was coated with a $0.22 \mu \mathrm{m}$ film of CP-Sil 5 CB (Chrompack B.V., Bergen op Zoom, The Netherlands), while the main column was coated with a $0.54 \mu \mathrm{m}$ film of methyl silicone (HP Ultra 1, Hewlett-Packard). The temperature program was as follows: $40^{\circ} \mathrm{C}(2$ min) to $160^{\circ} \mathrm{C}$ at $30^{\circ} \mathrm{C} \mathrm{min}^{-1}$ and then to $300^{\circ} \mathrm{C}(5 \mathrm{~min})$ at $5^{\circ} \mathrm{C} \mathrm{min}^{-1}$.

PCBs were analyzed using the same precolumn as used for the separation of the pesticides. The analytical column was a $30 \mathrm{~m} \times 0.32 \mathrm{~mm}$ i.d. capillary column coated with crosslinked methyl silicone (SE-30, Alltech, Deerfield, IL, USA). The film thickness of this column was $0.25 \mu \mathrm{m}$. The temperature was programmed from $40^{\circ} \mathrm{C}(2 \mathrm{~min})$ to $300^{\circ} \mathrm{C}(5 \mathrm{~min})$ at $10^{\circ} \mathrm{C} \mathrm{min}^{-1}$.

Helium was used as the carrier gas. The inlet pressure was $90 \mathrm{kPa}$. The temperature of the FID was $300^{\circ} \mathrm{C}$. Nitrogen was used as the auxiliary gas for the ECD. The ECD temperature was $330^{\circ} \mathrm{C}$. The precolumn effluent was vented during sample introduction and during the first $4 \mathrm{~min}$ of analysis.

Materials. Methylene chloride was purchased from Merck (Darmstadt, Germany) and was of analytical grade. It was additionally purified by distillation in an all glass apparatus equipped with a Vigreux column. Pesticide, Arachlor, and PCB congener standards were obtained from Accustandard (New Haven, CT, USA).

\section{RESULTS AND DISCUSSION}

The use of the ECD requires complete elimination of halogen-containing solvents from the chromatographic pathway. Even the minute quantities of methylene chloride that would enter the column in a conventional split injection of only $1 \mu \mathrm{L}$ of this solvent might perturb the ECD for the remainder of the chromatographic run. 
The performance of the system proposed here was first checked by testing its applicability for the introduction of small sample volumes. In the first series of experiments, samples of up to $1 \mu \mathrm{L}$ of methylene chloride were introduced into the twocolumn GC system in both the split and the splitless modes. In these experiments, no solvent elimination in the PTV was applied. The methylene chloride vapors were eliminated via the columnswitching device after elution from the precolumn. The precolumn was not back-flushed. Solvent removal was carried out solely by heart-cutting. In the experiment with split injection, no methylene chloride signal was observed on the ECD. The small amount of solvent introduced onto the precolumn was effectively removed in the heart-cutting step.

If $1 \mu \mathrm{L}$ of methylene chloride was introduced into the precolumn in the splitless mode, however, a sharp increase in the base line of the ECD was observed. Apparently, trace amounts of methylene chloride entered the main column, despite the heart-cutting step applied. This problem could be solved by applying a solvent vent step in the PTV prior to transferring the sample onto the precolumn. In this way the vast majority of solvent is eliminated before the sample enters the chromatographic pathway.

In a second series of experiments, large volumes of methylene chloride solutions were introduced using the PTV in the solvent vent mode. In this mode, solvent vapors are removed from the liner of the PTV via the split line. The amount of solvent that is introduced into the column during solvent venting was minimized by operating the injector at close to ambient inlet pressures [6]. The use of reduced inlet pressures during solvent elimination has two additional advantages. First, the speed of solvent elimination is enhanced due to the increased evaporation speed at lower pressures. More importantly, the ability to use low inlet pressures also allows reversal of the carrier gas flow through the precolumn during the solvent elimination process. This is a highly efficient means of minimizing the amount of solvent vapor actually transferred onto the precolumn. Only traces of solvent left in the liner after solvent elimination are introduced into the precolumn. These small amounts can be successfully eliminated by a heart-cutting step using a column-switching device, as is evidenced by Figures 2 and 3. These figures show chromatograms of large volume pesticide and PCB samples diluted in methylene chloride. As can be seen from the chromatograms, the methylene chloride is eliminated very efficiently. No methylene chloride peak is observed, which indicates that the amount of methylene chloride that reaches the ECD is below the detection limit of this extremely sensitive detector. The minor disturbances in the ECD signal that can be observed in the 5 to 10 min region are caused by trace impurities in the methylene chloride. The concentrations of the individual pesticides in Figure 2 were between $0.1 \mathrm{ppb}$ and $1 \mathrm{ppb}$. From the signal heights and the noise level observed in this chromatogram, the detection limits for these components are estimated to be in the 10 to $50 \mathrm{ppt}$ range. The total concentration of Arochlor 1260 in Figure 3 was approximately $5 \mathrm{ppb}$. The concentration of $\mathrm{PCB}$ 180 was approximately $250 \mathrm{ppt}$.

From the results presented in Figures 2 and 3 , it is clear that the system described here consisting of a PTV injector with a modified carrier gas inlet system and a two-column set-up is a powerful tool for complete elimination of solvents which may be incompatible with the detection system employed. The applicability of such a system is not limited to electron capture detection. A second detection system that might benefit from solvent removal is the nitrogen-phosphorous detector.

\section{REFERENCES}

1. G. Schomburg, J. Chromatogr. Sci. 21,97 (1983).

2. W.L. Tomberg, E. Dich-Hennes, and H. BüningPfaue, J. High Resolut. Chromatogr. 15, 279 (1992).

3. S.M. Sonchik, J. Chromatogr. Sci., 24, 22 (1986).

4. J. Staniewski and J.A. Rijks, in Proceedings of the 13th International Symposium on Capillary Chromatography, Riva del Garda, ltaly 1991, P. Sandra, Ed. (Hüthig Verlag, Heidelberg, 1991), p. 1334.

5. J. Staniewski and J.A. Rijks, J. High Resolut. Chromatogr. 16, 182 (1993).

6. J. Staniewski and J.A. Rijks, J. Chromatogr. 623, 105 (1992).

Received: May 27, 1993

Accepted: August 10, 1993 